\title{
Allergic bronchopulmonary aspergillosis
}

INSERM

\section{Source}

INSERM. (1999). Orphanet: an online rare disease and orphan drug data base. Allergic bronchopulmonary aspergillosis. ORPHA:1164

Allergic bronchopulmonary aspergillosis (ABPA) is a rare immunologic pulmonary disorder caused by hypersensitivity to Aspergillus fumigatus, clinically manifesting with poorly controlled asthma and recurrent pulmonary infiltrates. 